International Journal of Current Advanced Research

ISSN: O: 2319-6475, ISSN: P: 2319 - 6505, Impact Factor: SJIF: 5.995

Available Online at www.journalijcar.org

Volume 6; Issue 4; April 2017; Page No. 3162-3165

DOI: http://dx.doi.org/10.24327/ijcar.2017.3165.0212

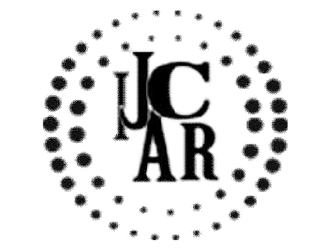

Review Article

\title{
STAINS ON PRIMARY TEETH- A REVIEW
}

\author{
Kayalvili Sanmugam
}

Saveetha Dental College, Saveetha University Chennai

\begin{tabular}{l}
\hline A R T I C L E I N F O \\
\hline Article History: \\
Received $15^{\text {th }}$ January, 2017 \\
Received in revised form $19^{\text {th }}$ February, 2017 \\
Accepted $21^{\text {st }}$ March, 2017 \\
Published online $28^{\text {th }}$ April, 2017
\end{tabular}

Key words:

Discoloration, Primary Dentition, Extrinsic, Intrinsic

\begin{abstract}
A B S T R A C T
The aim of this article is to review on the stains that are seen on the primary dentition. The objective of this article is to review the types of stains, the causes and the mechanisms involved in it. Stains on the permanent dentition has always been a matter of concern, however, this problem has also been observed in the primary dentition as well. Stains are the discolouration seen on the surface of the teeth which could be intrinsic or extrinsic. There are various reasons for the stains on primary dentition which could be congenital or due to any trauma along with other factors. Treatment of stains on primary dentition is as important as in the permanent dentition since it has a great impact on the self-esteem of the child.

It is important to bring awareness about the various types of stains on the primary dentition as this affects the aesthetic confidence of the child.
\end{abstract}

Copyright $\mathrm{O} 2017$ Kayalvili Sanmugam. This is an open access article distributed under the Creative Commons Attribution License, which permits unrestricted use, distribution, and reproduction in any medium, provided the original work is properly cited.

\section{INTRODUCTION}

A tooth can be divided into coronal and radicular portion. The coronal portion of the teeth is composed of enamel, dentin and pulp. Any changes in the coronal portion of the tooth causes alteration in the appearance of the tooth. This is due to the light transmitting and reflecting properties of these layers. The incident light and the quality of the reflected light influences the appearance of the tooth color. ${ }^{(1)}$

\section{Stains in Primary Dentition}

Stains are defined as any change in the color or translucency of the tooth due to any cause. Primary teeth are more commonly known as deciduous teeth, baby teeth or temporary teeth. $^{(2)}$ They are the first set of teeth that erupts in the oral cavity in the growth development of humans. They develop during the embryonic stage of development and they become visible in the mouth during infancy. They are usually lost and replaced by permanent teeth. In the absence of permanent replacements, primary teeth can remain functional for many years. Stains are discoloration of the tooth which is one of the most frequent reasons why a patient seeks dental care. Tooth discoloration is usually esthetically unpleasant and psychologically it affects both the children and the adult. ${ }^{(3)}$ There are some discolorations which are located on the outer surface of the tooth structure while others are caused by stain taken up by the enamel or dentin. Some occurs during tooth development and result in an alteration of the light transmitting properties of the tooth structures.

*Corresponding author: Kayalvili Sanmugam

Saveetha Dental College, Saveetha University Chennai
Tooth discolorations are caused by various factors like medications, genetic defects, caries, diseases, trauma, and normal aging processes. ${ }^{(4)}$

\section{Classification of stains}

The causes for tooth discoloration can be classified according to the location of the stains. It either can be extrinsic or intrinsic. ${ }^{(5,6,7)}$ Extrinsic discoloration lies on the tooth surface or in the acquired pellicle. The intrinsic discoloration occurs when the chromogens gets deposited within the bulk of the tooth, which maybe of local or systemic in origin. $^{(8)}$

\section{Extrinsic stains}

Extrinsic stains are defined as discoloration located on the outer surface of the tooth structure which is caused by extrinsic agents. ${ }^{(9)}$ Extrinsic stains can be divided into groups, which are direct and indirect. Direct staining is caused by compounds incorporated into the pellicle layer and the stain is a result of the basic color of the chromogen. It has multi-factorial etiology with the chromogens derived either from thesubstances habitually placed in the mouth or from the diet. Indirect staining is caused by a chemical interaction at the tooth surface. It is usually associated with cationic antiseptics and metal salts. These agents are without color or a different color from the stain produced on the tooth surfaces. $^{(10)}$

\section{Causes of Extrinsic Stains}

The factors which are responsible for the extrinsic stains are:

\section{Oral hygiene}



2. Diet
3. Medication factors
4. Environmental factors

\section{Types of Extrinsic Stains in Primary Dentition}

The types of stains which can be seen in primary teeth are:
1. Black Stain
2. Brown Stain
3. Orange Stain
4. Green Stain
5. Metallic Stain
6. Chlorhexidine Stain

\section{Black Stain}

Black stain is a extrinsic discolouration, which occurs along the cervical line of the buccal or lingual surfaces of teeth, particularly in the primary dentition. They appear early on the tooth enamel, at the age of 2 or 3 . Its negative effect on the dental aesthetic perception causes concerns in parents and can have significant effects on the self-confidence and personality of the child. ${ }^{(11)}$

\section{Mechanisms involved in Black Stain}

Iron is found in all living tissues including enamel, dentin and the dental pulp. ${ }^{(12,13)}$ Iron deficiency affects more than two billion people in the world and is one of the most common nutritional deficiencies. ${ }^{(14)}$ Although iron deficiency may sometimes result from defects in the body's ability to metaboliseiron, the most common cause is inadequate iron in the diet, a deficiency that is treatable by foods and supplements which contain iron salts. ${ }^{(14,15)}$ Iron salts in the form of supplements, usually drops or syrups fortified with folic acid and or vitamin. B12, are often prescribed to children below 5 years of age. ${ }^{(14)}$

Black extrinsic stains of bacterial origin are formed by ferric sulphide, which is a by-product of the reaction between hydrogen sulphide produced by bacteria and the iron ions present in saliva and gingival exudates [Reid et al., 1977]. These black stains are present as dots or small areas of dark coloration that may coalesce, forming a line that follows the contour of the marginal gingiva. They may also appear as diffuse stains, covering a great part of the tooth crown. The grooves, pits, and fissures can also be found to be impregnated with such pigmentation, which is difficult to remove, particularly in these areas [Koch et al., 2001]. ${ }^{(1)}$

\section{Factors Contributing to the Formation of Black Stain}

\section{Dietary habits \\ 2. Medication \\ 3. Chromogenic bacteria}

Dietary habits of the child contributes to the formation of black stains. Medications such as iron syrups which are given for children to treat anaemia will combine with hydrogen sulphide, produced by bacteriaand causes black stain. Chromogenic bacteria, most often Actinomyces species are well known to cause stains on the teeth. The bacteria produce hydrogen sulphideand reacts with iron in the saliva to form a bacterial plaque which causes black discolouration to the tooth.

\section{Treatment for Black Stain}

According to some investigators, these stains are related with a lower frequency of caries. ${ }^{(11)}$

The black stain particularly poses an aesthetic problem. Tooth brushing is not enough to remove this external stain. The professional cleaning is necessary to remove this stain.Although a simple scaling and tooth brushing with pumice powder are usually sufficient, frequently black stain is recurrent. The ultrasonic cleaning is not recommended, this modality can lead to enamel removal therefore, their repeated use is undesirable. Nevertheless, it can challenge the dentist, especially when it is deposited on roughened or pitted areas of the tooth. In a professional dental hygiene appointment, removal through polishing with rubber cup and fluoride pumice is possible. If the staining is resistant, the excess water can be blotted from the pumice and the tooth should be dried before the polishing procedure is performed. ${ }^{(16-19)}$ Also, sharp scaling instruments are of use against firmly attached deposit. Black stain tends to reform again despite good personal oral care, but quantity may be less when biofilm control procedures are meticulous. ${ }^{(16)}$

\section{Brown stain}

Brown stains on the surface of the teeth could be due to the deposition of tannins found in tea, coffee and other beverages. ${ }^{(5)}$

\section{Green Stain}

Green stain appears as a heavy grey green, soft and furry film, and has been attributed to fluorescent bacteria and fungi. ${ }^{(5)}$ This is more prevalent in males and associated with poor oral hygiene. ${ }^{(20)}$

\section{Orange Stain}

Orange stain is a light, thin deposit with a red to orange color. It is caused by chromogenic bacteria and it is found in a population with poor oral hygiene. ${ }^{(5)}$

\section{Metallic Staining}

Metallic stains, forms after industrial exposure to iron, manganese and silver. Iron containing oral solutions and mouth rinses which contains metal salts contributes to metallic stain. ${ }^{(21,22)}$

\section{Chlorhexidine stain}

Cationic antiseptics like chlorhexidine can cause staining after prolonged use. It is caused by the interaction of the cationic antiseptic chlorhexidine with dietary chromogens. ${ }^{(23)}$

\section{Intrinsic Stains}

Intrinsic discolouration occurs following a change to the structural composition or thickness of the dental hard tissues. The normal colour of teeth is determined by the blue, green and pink tints of the enamel and is reinforced by the yellow through to brown shades of dentine beneath. A number of metabolic diseases and systemic factors are known to affect the developing dentition and cause discolouration as a consequence. Local factors such as injury are also recognised. ${ }^{(24)}$ The metabolic disorders which affect the dentition during its formation are: 


\section{Alkaptonuria}

This inborn error of metabolism results in incomplete metabolism of tyrosine and phenylalanine, which promotes the build up of homogentisic acid. This affects the permanent dentition by causing a brown discolouration. ${ }^{(25)}$

\section{Congenital erythropoietic porphyria}

This is a rare, recessive, autosomal, metabolic disorder in which there is an error in porphyrin metabolism leading to the accumulation of porphyrins in bone marrow, red blood cells, urine, faeces and teeth. A red-brown discolouration of the teeth is the result and the affected teeth show a red fluorescence under ultra-violet light. ${ }^{(26)}$

\section{Tetracycline staining}

Systemic administration of tetracyclinesduring development is associated with deposition of tetracycline within bone and the dental hard tissues. ${ }^{(27,28)}$ Urist and Ibsen ${ }^{(29)}$ suggested that tetracycline and its homologues have the ability to form complexes with calcium ions on the surface of hydroxy apatite crystals within bone and dental tissues. Dentine has been shown to be more heavily stained than enamel. ${ }^{(30)}$ Tetracycline is able to cross the placental barrier and should be avoided from 29 weeks in utero until full term to prevent incorporation into the dental tissues. Since the permanent teeth continue to develop in the infant and young child until 12 years of age, tetracycline administration should be avoided in children below this age and in breast-feeding and expectant mothers. ${ }^{(30)}$ The most critical time to avoid the administration of tetracycline for the deciduous dentition is 4 months in utero to 5 months post-partum, with regard to the incisor and canine teeth. In the permanent dentition, for the incisor and canine teeth, this period is from 4 months post-partum to approximately 7 years of age. ${ }^{(31)}$ The colour changes involveddepend upon the precise medication used, the dosage and the period of time over which the medication was given. Teeth affected by tetracycline have a yellowish or brown-grey appearance which is worse on eruption and diminishes with time. Exposure to light changes the colour to brown, the anterior teeth are particularly susceptible to light induced colour changes. ${ }^{(32)}$

\section{Fluorosis}

The association between fluoride intake and its effect on enamel was noted by Dean as long ago as $1932 .{ }^{(33)}$ This may arise endemically from naturally occurring water supplies or from fluoride delivered in mouthrinses, tablets or toothpastes as a supplement. The severity is related to age and dose. Birdsong-Whitford et al. ${ }^{(34)}$ gave evidence for the possible increased affect of fluorosis at altitude with their work on rodents. The enamel is often affected and may vary from areas of flecking to diffuse opacious mottling, whilst the colour of the enamel ranges from chalkywhite to a dark brown or black appearance. The brown or black discolouration is posteruptive and probably caused by the internalisation of extrinsic stain into the porous enamel. ${ }^{(35)}$

\section{Pulpal haemorrhagic products:}

The discolouration of teeth following severe trauma was considered to be caused by pulpal haemorrhage. Haemolysis of the red blood cells would follow and release the haem group to combine with the putrefying pulpal tissue to form black iron sulphide. Grossman asserted in 1943 that the depth of dentinal penetration determines the degree of discolouration; ${ }^{(36)}$ there was little if any scientific investigation of this hypothesis. In vitro studies have recently shown that the major cause of discolouration of non-infected traumatised teeth is the accumulation of the haemoglobin molecule or other haematin molecules. In the absence of infection, the release of iron from the protoporphyrin ring is unlikely. This greater understanding of the nature of tooth staining following trauma to teeth may be of importance if the manufacture of bleaching agents, with specific activity, becomes possible. For instance, with further analysis it may become possible to develop a bleaching agent for use on teeth stained specifically by blood pigments. ${ }^{(37)}$ Incidentally, it has been shown that the pinkish hue seen initially after trauma may disappear in 2 to 3 months if the tooth becomes revascularised. ${ }^{(38)}$

\section{Congenital hyperbilirubinaemia}

Hyperbilirubinemia results in elevated serum levels of bilirubin and it is chemically defined as a serum concentration of bilirubin larger than $1,5 \mathrm{mg} / 100$ mL.During hyperbilirubinemia bilirubin is deposited throughout the body. In the hard tissues bilirubin is permanently trapped, as these tissues lose their metabolic activity after maturation. ${ }^{(39)}$ When hyperbilirubinemia occurs during the period of tooth development, serum bilirubin may be deposited in the dental hard tissues and cause a green stain. ${ }^{(40)}$ The pigmentation is always brightest when the tooth first erupts and fades as the child grows older. A possible explanation for these changes of the color is the change of the translucency of deciduous enamel with age, and this interferes with the transmission of the green stain from the underlying dentin. ${ }^{(39)}$

\section{CONCLUSION}

In the management of patients with discolored tooth, an understanding of the mechanism behind the discoloration is of relevance to the dental practitioner as it can be valuable in the decision-making process when considering how to treat the condition. Prevention of avoidable causes of tooth staining is important, the general dental practitioner may be able to offer advicetomedical colleagues when alternative therapy is available. A grasp of the pathological processes involved in tooth staining can assist in explaining the cause to anxious or concerned parent. When recommending or prescribing oral care products known to cause staining, it is important to warn patients of such potential side effects. In understanding the mechanism of stain formation associated with cationic antiseptics and metal salts, notably stannous fluoride, advising patients in respect of the more chromogenic dietary fluids may help prevent or limit tooth staining.

\section{References}

1. Watts, A. and M. Addy, Tooth discolouration and staining: a review of the literature. Br Dent J, 2001. 190(6): p. 309-16.

2. $\quad \boldsymbol{a} \boldsymbol{b}$ Illustrated Dental Embryology, Histology, and Anatomy, Bath-Balogh and Fehrenbach, Elsevier, 2011, page 255

3. Manuel ST, Abhishek P, Kundabala M, Etiology of tooth discoloration- a review, Nig Dent $J$ Vol 18 No. 2 July - Dec 2010 
4. Lotte Jenssen and Huy Quoc Tran,Classificationof severe tooth discolorations and treatment options

5. Hattab FN, Qudeimat MA, al-Rimawi HS. Dental discoloration: an overview. $J$ Esthet Dent 1999; 11:291310.

6. Sulieman M. An overview of tooth discoloration: extrinsic, intrinsic and internalized stains. Dent Update. 2005; 32:463-471.

7. Dayan D, Heifferman A, Gorski M, Begleiter A. Tooth discoloration: extrinsic and intrinsic factors. Quintessence Int 1983; 14:195-199.

8. Vogel RI. Intrinsic and extrinsic discoloration of the dentition. J Oral Med 1975; 30:99-104.

9. Eriksen HM, Nordbø H. Extrinsic discoloration of teeth. J ClinPeriodontol 1978; 5: 229-236.

10. Natto SA. Chemistry and mechanism of extrinsic and intrinsic discoloration. J Am Dent Assoc 1997; 128 Suppl: 6S- 10S.

11. FawziRachid1* and Hariri El Mehdi2, Black Stains in Primary Teeth: Overview, Rachid and Mehdi, Pediatr Dent Care 2016, 1:4

12. Eshghi A, Kowsari-Isfahan R, Rezaiefar M, Razavi M, Zeighami S. Effect of iron containing supplements on rats' dental caries progression. $J$ Dent (Tehran). 2012;9(1):14

13. Wen X, Paine ML. Iron deposition and ferritin heavy chain (Fth) localization in rodent teeth. BMC Res Notes. 2013; 6:1

14. De-Regil LM, Jefferds ME, Sylvetsky AC, Dowswell $\mathrm{T}$. Intermittent iron supplementation for improving nutrition and development in children under 12 years of age. Cochrane Database Syst Rev. 2011;7(12):CD009085.

15. Adcock KG, Hogan SM. Extrinsic iron staining in infant teeth from iron-fortified formula and rice cereal. J PediatrPharmacolTher. 2008; 13(3):162-5.

16. Saba C, Solidani M, Berlutti F, Vestri A, Ottolenghi L, et al. (2006) Black stains in the mixed dentition: a PCR micro-biological study of the etiopathogenic bacteria.

17. J ClinPediatric Dent 30: 219-224. 13. Theilade J (1977) Development of bacterial plaque in the oral cavity.

18. JClinPeriodontol 4: 11-12. 14. Wilkins EM (2005) Clinical practice of the dental hygienist (9thedn) Philadelphia:

19. Lippincott Williams \& Wilkins 316-317. 15. Bonecker M, Cleaton-Jones P (2003) Trends in dental caries in Latin American and Caribbean 5-6 and 11-13-year-old children: a systematic review. Community Dent Oral Epidemiol 31: 152-157.

20. Sarkonen N, Kononen E, Summanen P, Kanervo A, Takala A, et al. (2000) Oral colonization with Actinomyces species in infants by two years of age. J Dent Res 79: 864-867.

21. Waerhaug M, Gjermo P, Rølla G, Johansen JR. Comparison of the effect of chlorhexidine and CuSO4 on plaque formation and development of gingivitis.
22. J ClinPeriodontol 1984; 11:176-180. 26. Ellingsen JE, Eriksen HM, Rölla G. Extrinsic dental stain caused by stannous fluoride. Scand J Dent Res 1982; 90:9-13.

23. Tredwin CJ, Scully C, Bagan-Sebastian JV. Druginduced disorders of teeth. J Dent Res 2005; 84:596602.

24. A. Watts, and M. Addy, Tooth discolouration and staining: a review of the literature. British Dental Journal Volume 190 No.6 March 242001

25. 8 Link J. Discolouration of the teeth in alkaptonuria and Parkinsonism. Chron Omaha Dist Dent Soc 1973; 36: 136.

26. Fayle S A, Pollard M A. Congenital erythropietic porphyria-oral manifestations and dental treatment in childhood: a case report. Quintessence Int 1994; 25: 551-554.

27. Shields E D, Bixler D, El-Kafrawy A M. A proposed classification for heritable dentine defects with description of a new entity. Arch Oral Biol 1973; 18: 543-553.

28. Wallman I S, Hilton H B. Teeth pigmented by tetracycline. Lancet 1962; I: 827-829. 20

29. Weymann J, Porteous J R., Discolouration of the teeth probably due to administration of tetracyclines: A preliminary report. Br Dent $J 1962 ; 113$ : 51-54. 21

30. Urist $\mathrm{M} \mathrm{R}$, Ibsen $\mathrm{K} \mathrm{H}$. Chemical reactivity of mineralised tissue with oxytetracycline. Arch Pathol (Chicago) 1963; 76: 484-496.

31. British National Formulary, March 1999; 37: 254256, BMJ Books: London, UK.

32. Moffitt J M, Cooley R O, Olsen N H, Hefferen J J. Prediction of tetracycline induced tooth discolouration. J Am Dent Assoc 1974; 88: 547-552.

33. Dean H T. Chronic endemic dental fluorosis. JAMA 1932; 107: 1269.

34. Birdsong-Whitford N L, Dickinson A, Whitford G M. Effect of haematocrit on plasma $\mathrm{F}$ concentration. $J$ Dent Res 1984; 184: Abstract No. 129.

35. Weatherall J A, Robinson C, Hallsworth A S. Changes in the fluoride concentration of the labial surface enamel with age. Caries Res 1972; 6: 312324.

36. Grossman L. Root canal therapy. 2nd ed. pp 347349. Philadelphia: Lea and Febiger, 1943.

37. Marin P D, Bartold P M, Heithersay G S. Tooth discolouration by blood: an in vitro histochemical study. Endod Dent Traumatol 1997; 13: 132-138.

38. Andraesen F M. Transient apical breakdown and its relation to colour and sensibility changes after luxation injuries to teeth. Endod Dent Traumatol 1986; 2: 9-19.

39. Guimaraes, L.P. and T.A. Silva, Green teeth associated with cholestasis caused by sepsis: a case report and review of the literature. Oral Surg Oral Med Oral Pathol Oral RadiolEndod, 2003. 95(4): p. 446-51.

40. Amaral, T.H., et al., Tooth pigmentation caused by bilirubin: a case report and histological evaluation. Spec Care Dentist, 2008. 28(6): p. 254-7. 